\title{
PRODUÇÃO DE SENTIDOS ACERCA DA FAMÍLIA QUE CONVIVE COM O DOENTE MENTAL
}

Rozemere Cardoso de Souza ${ }^{1}$

Maria Cecília Morais Scatena ${ }^{2}$

Souza RC, Scatena MCM. Produção de sentidos acerca da família que convive com o doente mental. Rev Latino-am Enfermagem 2005 março-abril; 13(2):173-9.

A assistência às famílias é, hoje, um grande desafio da prática em Saúde Mental, exigindo dos profissionais estudos e aproximação desses atores sociais. Este estudo, norteado por abordagem construcionista social e qualitativa, objetivou conhecer os sentidos dados por profissionais do Programa de Saúde da Família (PSF) acerca da família que convive com o doente mental. Obtiveram-se os dados por meio de grupo focal, com membros de duas equipes do PSF, em Ilhéus/Bahia. Como resultados, descrevem-se a família e suas inscrições conceituais, assim como os sentidos de: cuidadora; motivadora e sofredora de preconceitos; impotente e carente de recursos; produtora de maus-tratos e desequilibrada. Desses sentidos produzidos, constatou-se que uns servem para reforçar a exclusão do doente mental e de sua família, na comunidade, e outros rompem com esse discurso, podendo favorecer a aproximação entre esses atores e os profissionais, a favor de uma nova prática que melhore as condições de suas vidas.

DESCRITORES: família; saúde mental; enfermagem

\section{PRODUCTION OF MEANINGS ABOUT FAMILY MEMBERS LIVING WITH MENTALLY-ILL PATIENTS}

Nowadays, family care is a great challenge for Mental Health practice, which requires professionals to study and take a closer look at these social actors. This study, which is guided by a social constructionist and qualitative approach, aimed to get to know the meanings Family Health Program (FHP) professionals attribute to family members living with mentally-ill patients. Data were collected by means of the focus group technique, involving members from two FHP teams in Ilhéus/Bahia, Brazil. As a result, we describe the family members and their conceptual registers, as well as the following meanings: caring, motivating and suffering prejudice; powerless and lacking resources; producing abuse and unbalanced. It was observed that some of these meanings reinforce the community's exclusion of mental patients and their family members, while others oppose this discourse and are thus able to favor a closer approximation between these actors and the professionals, in view of a new practice that improves their living conditions.

DESCRIPTORS: family; mental health; nursing

\section{PRODUCCIÓN DE SENTIDOS ACERCA DE LA FAMILIA QUE CONVIVE CON EL ENFERMO MENTAL}

La atención a las familias constituye hoy un gran desafío de la práctica en Salud Mental, exigiendo de los profesionales estudios y aproximación de eses actores sociales. La finalidad de este estudio, orientado por una aproximación construccionista social y cualitativa, fue la de conocer los sentidos dados por profesionales del Programa de Salud de la Familia (PSF) acerca de la familia que convive con el enfermo mental. Obtuvimos los datos mediante la técnica del grupo focal con miembros de dos equipos del PSF en Ilhéus/Bahia, Brasil. Como resultados, describimos a la familia y sus registros conceptuales, así como los sentidos de: cuidadora; motivadora y sufridora de prejuicios; impotente y falta de recursos; productora de maltratos y desequilibrada. De esos sentidos producidos, constatamos que algunos sirven para reforzar la exclusión del enfermo mental y su familia en la comunidad, y que otros rompen con este discurso, lo que puede favorecer la aproximación entre esos actores y los profesionales, a favor de una nueva práctica que mejore las condiciones de sus vidas.

DESCRIPTORES: familia; salud mental; enfermería

\footnotetext{
${ }^{1}$ Doutor em Enfermagem pela Escola de Enfermagem de Ribeirão Preto, da Universidade de São Paulo, Professor Assistente da Universidade Estadual de Santa Cruz, Ilhéus/BA, e-mail: rozemeresouza@ig.com.br; ${ }^{2}$ Professor Associado da Escola de Enfermagem de Ribeirão Preto, da Universidade de São Paulo, Centro Colaborador da OMS para o desenvolvimento da pesquisa em enfermagem, e-mail: cilamorais@hotmail.com.br
} 


\section{INTRODUÇÃO}

Dois desafios atuais apresentam-se no campo da Saúde: compreender as famílias, considerando-se a especificidade e a diversidade dos contextos culturais onde estão inseridas, e prestarIhes assistência condizente com esses contextos e sua dinâmica própria.

Perseguir esses desafios implica aproximações e relacionamentos entre profissionais de saúde e famílias, os quais resultem numa construção conjunta de possibilidades terapêuticas. Implica também o profissional "deixar de lado" idéias pré-concebidas acerca da família, as quais podem dificultar-lhe a visualização de ações e recursos locais que favoreçam o cuidado.

Assim, entendemos que as concepções que o profissional tiver acerca da família e a forma como faz uso delas, em muito definirá suas intervenções, contribuindo ou não para a melhoria da qualidade de vida familiar. Por exemplo: ao conceber a família como homogênea ou como culpada pelo surgimento da doença, corre-se o risco de estabelecer com ela uma relação de imposição, em vez de tê-la como participante do cuidado e como um grupo social que precisa de ajuda ${ }^{(1)}$. Esse é um exemplo que vem se repetindo nas relações entre profissionais e famílias que convivem com a enfermidade mental.

Para essas famílias, o aparecimento da enfermidade mental e suas conseqüências fazem agravar eventuais conflitos e dificuldades do cotidiano, anteriormente enfrentados por elas. Não há dúvidas de que precisam de ajuda para lidar com essas questões e outras, como a culpa, a sobrecarga, o pessimismo e 0 isolamento social, que surgem do sofrimento que a loucura imprime, tanto para eles quanto para a pessoa que adoece ${ }^{(2)}$.

Na tentativa de ajudá-los, nem sempre os profissionais de saúde mental foram eficazes em suas ações, contribuindo, inclusive, com teorias e práticas para confirmar a culpa na gênese da doença mental. Curiosamente, as propostas advindas da Reforma psiquiátrica têm produzido desassistência, com a devolução do doente mental à família sem o devido conhecimento das suas reais necessidades e condições, em termos materiais, psicossociais, de saúde e qualidade de vida ${ }^{(3)}$.

Compartilhando de que não é essa a intenção da Reforma, algumas reflexões acerca dessa temática vêm sendo introduzidas na literatura. Os profissionais, muitas vezes, trabalham com a concepção de uma família idealizada ${ }^{(4-5)}$, de maneira que precisam se desprender de preconceitos e compreender a família em sua singularidade, dando o suporte necessário, a fim de efetivá-la como parceira e alvo do cuidado em Saúde Mental. A família e a assistência precisam ser pensadas em suas múltiplas dimensões, a fim de se descobrirem possibilidades de intervenção e de ajuda. É preciso dar-se conta das implicações políticas que há nas distinções que são feitas entre profissionais e familiares e entre estes e o membro doente e todo 0 corpo social. Nesse sentido, é preciso, ainda, construir um novo paradigma e, conseqüentemente, uma nova linguagem, que possa dar conta da complexidade dessas questões, apoiando-se na participação e no desenvolvimento de projetos que alarguem os espaços de liberdade dos sujeitos.

Devemos, pois, repensar o cuidado às famílias que convivem com o doente mental, não como um fenômeno definido em si mesmo, mas dentro de um paradigma que favoreça a diversidade de diálogos e, assim, de construções - saberes e ações - entre profissionais e entre estes e as famílias.

Na emergência de um novo paradigma, surge a perspectiva construcionista social, como uma estratégia para mudança, por se tratar de uma teoria que trabalha com a construção e reconstrução das coisas e das pessoas, a partir da interação entre elas.

É sob essa perspectiva, da qual falaremos mais adiante, que este trabalho se desenvolveu, como uma prática dialógica, e buscou responder a questionamentos como: o que pensam os profissionais de saúde da família acerca da família do doente mental? Como lidam com essas famílias em seu cotidiano profissional? E quais os sentidos que favorecem ou dificultam o cuidado em relação a elas?

Dessa maneira, este estudo propõe conhecer os sentidos que os profissionais de saúde da família dão às famílias que convivem com a enfermidade mental.

Os sentidos referem-se a uma construção social, por meio da qual as "pessoas constroem os termos a partir dos quais compreendem e lidam com as situações e fenômenos em sua volta" ${ }^{(6)}$. Assim, os sentidos são produzidos nas diversas práticas dialógicas, possibilitando-nos entender pensamentos, padrões sociais e posicionamentos de pessoas, como também descobrir/ construir formas de ação para dissolução de problemas ${ }^{(7)}$.

Por sua vez, o contexto do Programa de Saúde da Família (PSF) foi escolhido por ser um espaço rico para a produção de sentidos acerca da família, justificado, dentre outros aspectos, por sua finalidade de instaurar uma nova prática sanitária e promover a saúde das famílias, considerando-as em todos os seus espaços de vida; característica de trabalho em equipe; proximidade com as pessoas, porque atende a uma área geográfica delimitada; e pelo fato de os agentes comunitários de saúde serem membros da comunidade onde atuam, participantes, então, de situações experimentadas pelas famílias em questão.

Este trabalho resulta, também, da pesquisa que buscou construir sentidos acerca do doente mental e dos cuidados dirigidos a ele, no contexto do PSF, cuja produção se apresenta numa tese de doutorado ${ }^{(8)}$. Aqui, são analisados os trechos de conversas referentes às famílias do doente mental, produzidos por duas equipes do PSF.

A importância deste trabalho está em fomentar a reflexão entre profissionais do PSF acerca da família que convive com o doente mental, entendendo que refletir sobre a própria prática já é um meio de 
transformá-la; construir sentidos que possam servir de ferramentas aos profissionais de saúde mental que oferecem ou desejam oferecer suporte aos profissionais de saúde da família no cuidado dirigido às famílias dos doentes mentais; e subsidiar reflexões acerca do tema Família e Saúde Mental, tão necessárias nos dias atuais, entre os diversos profissionais de saúde, uma vez que a ajuda às famílias é algo imprescindível e urgente.

\section{REFERENCIAL TEÓRICO-METODOLÓGICO}

Trata-se de uma pesquisa qualitativa que nos possibilitou a produção de sentidos por profissionais de saúde da família acerca da família que convive com a enfermidade mental.

Nossa intenção com a escolha dessa abordagem metodológica foi valorizar as vozes dos participantes e as interações desenvolvidas com uma das pesquisadoras, ou seja, o campo da intersubjetividade que é favorecido por essa pesquisa.

Com relação ao referencial teórico, optamos pelo construcionismo social, por entender a pesquisa como uma prática dialógica, uma ação que conduz à construção de problemas e possibilidades de modo compartilhado ${ }^{(9)}$.

Nessa perspectiva, o conhecimento não é representado, pois não se trata de algo que se possui, mas que se "constrói em coletividade", em tempo e espaço específicos. Assim, o conhecimento situa-se no espaço da interpessoalidade, da relação com o outro, esteja ele presente ou não ${ }^{(6)}$.

Tem-se em todas as práticas dialógicas a produção de sentidos e de posicionamentos de pessoas. Essas constituem os focos centrais de análise na abordagem construcionista e são construídas por uma multiplicidade de vozes, advindas da religião, da arte, da filosofia, da ciência e de outros saberes.

Os sentidos, aqui, são analisados por meio do uso feito pelos participantes dos repertórios interpretativos acerca da família do doente mental, nas conversas desenvolvidas. Os repertórios são definidos como o "conjunto de termos, descrições, lugares-comuns e figuras de linguagem que demarcam o rol de possibilidades de construções discursivas, tendo por parâmetros o contexto em que essas práticas são produzidas e os estilos gramaticais específicos"(6).

Partindo dessa compreensão, valorizamos a dinâmica das relações num tempo e contexto determinados, os discursos por elas proferidos e, principalmente, a pesquisa, por possibilitar a promoção de relações que favoreçam diálogos e reflexões sobre o tema em questão.

O trabalho de campo ocorreu numa área urbana do município de Ilhéus/ Bahia, onde atuam duas equipes do PSF há mais de um ano: Nossa Senhora da Vitória I e II. Os participantes foram: um médico, uma enfermeira e doze agentes comunitários de saúde, que atenderam aos critérios de inclusão: concordar em participar da pesquisa e atuar no programa por mais de um ano.

Para a coleta de dados, formaram-se dois grupos focais de sessão única, nos meses de junho e dezembro de 2003. Em cada grupo, uma equipe de saúde da família, que foi convidada a se reunir no espaço de uma igreja da área onde atuava, sendo respeitados os princípios éticos de participação voluntária, esclarecida e consentida. As conversas tiveram uma duração média de uma hora e vinte minutos. Seguimos um guia de temas, sendo que, para este trabalho, foram analisados apenas os trechos de conversas relacionadas à família.

A análise deu-se em dois momentos: construção de mapas de associação de idéias e síntese temática dos mapas, onde se buscaram, também, elos com a literatura da área e a identificação dos padrões de relacionamentos sustentados ou suprimidos nos sentidos identificados.

\section{RESULTADOS E DISCUSSÕES}

Partindo da análise dos trechos de conversas que abordavam a família do doente mental, agrupamos repertórios interpretativos em torno de seis temas, a saber: a) a família inscrita por laços consangüíneos e afetivos; b) a família como cuidadora e alvo do cuidado em saúde; c) a família como motivadora e sofredora de preconceitos; d) a família impotente e carente de recursos; e) a família como produtora de maustratos; f) a família desequilibrada.

Cabe salientar que os nomes próprios citados foram substituídos por designações fictícias.

a) A família inscrita por laços consangüíneos e afetivos

Nesse tema, agrupamos repertórios cujo sentido de uso atribuíam conceitos à família do doente mental tanto por laços consangüíneos (mãe, pai, irmão, cônjuge), quanto por laços afetivos, como um conjunto de profissionais de um Centro de Atenção Psicossocial (CAPS) que é descrito, por um participante, como a família do doente, considerando as relações construtivas que desenvolvia.

(...) eu vou referir aqui não só à própria família, mas também à família como as pessoas com quem o doente convive... num ambiente (referindo-se ao CAPS) que ele se sente bem (João - Grupo 1).

Família é entendida, pois, como sendo todos aqueles que estão próximos a ela e que exercem influência direta sobre os seus membros $^{(10)}$.

Esse conceito, construído a partir das relações afetivas, é importante para a existência do doente mental, principalmente para aqueles que não podem contar com a própria família ou que são por 
ela rejeitados ou abandonados. Isso se justifica pelo fato de a família afetiva significar que o doente não está sozinho no mundo e que ele tem um lugar onde pode se abrigar.

O doente mental deverá contar com as pessoas com quem poderá se relacionar para superação dos obstáculos advindos do sofrimento mental e de seu tratamento ${ }^{(10)}$, sendo que é para essas mesmas pessoas que os profissionais de saúde deverão dirigir sua atenção.

Por isso, tal compreensão nos remete, ainda, ao entendimento de que o conceito de família não deve ser "naturalizado" pelos profissionais de saúde, nem se restringir à família nuclear ou extensa ${ }^{(11)}$, mas visto sob a ótica da diversidade organizacional. "A apreensão dessa diversidade é relevante, pois o pertencimento social e cultural da família e cada uma das modalidades de sua ordenação condicionam e delimitam as possibilidades de cuidados com a saúde e de atendimento a doentes $^{\prime \prime(12)}$.

A implicação desse sentido é, portanto, uma abertura para entender a família, conforme a dinâmica que nela se desenvolve e 0 "conjunto de vínculos interpessoais significativos do sujeito: amigos, relações de trabalho, vínculos na comunidade, grupos sociais e políticos" ${ }^{\prime \prime(11)}$. O uso operacional desse conceito, pautado em aspectos como acolhimento, segurança, vida doméstica, solidariedade e cuidado, servem, ainda, para ampliar o espaço de intervenção dos profissionais de saúde, a fim de preservar a saúde mental de todos os membros da família.

b)A família como cuidadora e alvo do cuidado em saúde

Aqui, agrupamos os repertórios cujos sentidos explicitavam a família como uma necessidade premente do doente mental e como 0 lugar privilegiado para seu tratamento. Cuidado e responsabilidade permearam tais construções.

Esse tratamento (do doente mental) tem que ser com a família, na maioria das vezes... é só a família ser orientada a fazer esse trabalho, não deixar nunca de dar o remédio... (Pedro - Grupo 1).

Como cuidadora, algumas responsabilidades são delegadas à família que convive com o doente mental. Além das que se apresentam na fala acima, citam-se: respeito à sua liberdade; favorecimentos de relações, interesse e tratamento, sem agressões; mudanças do estilo de vida. Com relação a essa última citação, é destacado, nas falas de alguns dos participantes, que falta vontade ou orientação do familiar para que efetive essa mudança a favor do cuidado dirigido ao doente mental.

A atenção, a importância de o familiar mudar o estilo de vida por causa do outro (que adoece). Ninguém está querendo isso ou tem essa disposição e entende que isso é fundamental (Marina - Grupo 2).

Esses sentidos enfocam um papel social da família: a de cuidadora do membro que adoece, cuja importância vem sendo destacada pela literatura ${ }^{(1,12)}$. Dentro desse papel, encontram-se as funções de perceber sintomas e procurar soluções, as quais se inserem, quase que exclusivamente, no universo feminino. Isso significa que a mulher - dona de casa, mãe, irmã, vizinha - tem se ocupado da responsabilidade de cuidar do doente, tarefa tida como "árdua" para muitas delas $^{(3)}$.

Como cuidadora da saúde e da doença de seus membros e, particularmente, do membro que adoece mentalmente, a mulher se vê, freqüentemente, impossibilitada de participar do mercado de trabalho, sofre sobrecarga, afetando a qualidade de vida da unidade doméstica, e precisa da ajuda do poder público ${ }^{(12)}$.

Decorrente disso, outro sentido foi produzido pelos participantes, o de ter a família como foco do cuidado em saúde.

Lá (um serviço de saúde mental) cuida exclusivamente da pessoa com problema mental, mas não cuida da família, não a orienta, de maneira que ela em casa consiga se adaptar à nova realidade (Cláudio).

Que é uma dura realidade... (Marina - Grupo 2).

Essas vozes pontuam necessidades da família. Muitos trabalhos apontam para a sobrecarga por ela sofrida ${ }^{(2,5,11)}$, exigindo apoio e outros recursos que facilitem a convivência com o doente mental, e reforçam a idéia de que quem cuida precisa ser cuidado.

A sobrecarga vem sendo definida como os "encargos econômicos, físicos e emocionais a que os familiares estão submetidos e o quanto a convivência com um paciente representa em peso material, subjetivo, organizativo e social", de maneira que não há dúvida de que precisam de ajuda. Profissionais de saúde mental dedicados puderam freqüentemente ajudar pessoas em busca de alianças e bons encontros, por meio de terapias ou grupos familiares e de intervenções psicoeducativas ${ }^{(2)}$.

É interessante notar, no entanto, que os participantes deste estudo, reconhecendo parte desses encargos, pouco fizeram referência a como poderiam ajudar essas famílias, apesar de participarem de um Programa que se dirige à sua saúde. Isso foi justificado pela referência de "não saber como lidar" com tais situações.

... Às vezes, a gente está vendo que ali tem que ser feito algum trabalho, mas você olha para um lado, olha para outro e diz assim - como eu vou fazer? (Cláudio).

O que é que eu vou fazer?... (Roberta - Grupo 1).

Para as famílias, um apoio vem sendo encontrado nas diversas instâncias religiosas que, segundo os profissionais investigados, constituem o recurso mais próximo das famílias, na comunidade, favorecendo-Ihes explicações, apoio e, eventualmente, cura da pessoa que sofre mentalmente.

Outros dois aspectos chamaram nossa atenção nesses discursos e incluem: a responsabilização exclusiva da família pelo cuidado do doente, inviabilizando os participantes de pensarem sobre 
suas próprias responsabilidades, pelo cuidado dispensado a essas pessoas, e a total dependência do doente mental em relação à sua família, inviabilizando a possibilidade de autonomia no curso do seu desenvolvimento e de participação na implementação de seus cuidados.

Sem querer esgotar tal discussão, esses sentidos também apontam para a necessidade de suporte aos profissionais de saúde da família, viabilizando a construção de diálogos e de cuidados, por meio de sua prática comunitária, com as famílias que lidam com a enfermidade mental. Diálogos porque, como cuidadora, é preciso que os profissionais compartilhem de crenças, valores e práticas de que a família se utiliza para realizar o cuidado, como também compartilhem de outros saberes a esse respeito. E cuidados porque não haverá uma única forma para atender às necessidades da família, mas, sim, uma diversidade, consoante os recursos geográficos e sociais onde ela se situar.

\section{c) A família como motivadora e sofredora de preconceitos}

Nesse tema, foram incluídos os repertórios usados pelos participantes, para explicitar: o preconceito afirmado pela família, manifestado por suas atitudes de esconder a pessoa doente, ter sentimentos de vergonha e usar palavras depreciativas para referirse ao doente mental; e o preconceito que ela sofre entre vizinhos e comunidade em geral.

\section{(...) (podemos) tranqüilizar a família também, porque, já que a} sociedade estigmatiza, a própria família tem aquilo (o estigma) dentro deles, tem vergonha do filho. Quando a gente vai visitar uma casa dessas, falam logo "eu tenho uma filha lelé da cuca, tam-tam, perturbada" e dizem "vai pra lá, menina". E escondem. Então, a própria família discrimina... (Letícia - Grupo 2).

... de um modo geral, a primeira atitude da família é tentar internar o doente, excluí-lo ou até mesmo omitir que ele pertence à família... (Pedro Grupo 1).

A família estigmatiza seu doente a partir da distinção de que ele é diferente e precisa ser tratado de forma diferente ${ }^{(10)}$. Para algumas, apresentar um irmão ou um filho doente é um fato absolutamente intolerável, inaceitável ${ }^{(2)}$.

As conseqüências desses sentidos, exemplificadas nas falas acima, inscrevem a exclusão social do doente mental, assim como da própria família, na comunidade, e são "decisivamente influenciadas pelos valores e representações acerca da loucura, presentes em um determinado momento histórico"(2).

A proliferação de uma linguagem ligada a déficit, no âmbito do processo saúde/doença mental, contribui para a propagação de sutis, mas desleais hierarquias sociais, resultando em práticas de distanciamento e degradação e, ainda, na admissão das pessoas que são assim rotuladas em programas de internação institucional ${ }^{(13)}$, excluindo-os da convivência na comunidade, onde têm um grau zero de trocas. Quanto aos seus familiares, o convite é para um progressivo isolamento da vida comunitária ${ }^{(11)}$.

Uma outra implicação desses sentidos para os participantes está na compreensão de que as famílias precisam ser trabalhadas com relação à desfamiliarização desse preconceito, expressa na fala de que o profissional precisa "tranqüilizar a família". No decorrer das conversas, outros participantes concordam com tal necessidade e com o fato de que eles precisam ser capacitados para não apenas ajudálas a enfrentar essa situação, como também contribuir para a inclusão do doente mental em seu contexto.

Sob essa compreensão, a família, a pessoa doente e os profissionais precisam explorar novos sentidos e representações. Precisam de espaços de liberdade de expressão, que possibilitem encontrar formas mais genuínas de exercitar a subjetividade, resgatando o valor da alteridade e do trabalho coletivo ${ }^{(2)}$, à procura de transformações que possam melhorar a vida de todos.

d)A família impotente e carente de recursos

Os repertórios que fizeram aflorar esse tema, falam-nos dos recursos que faltam às famílias que convivem com o doente mental, gerando nelas um sentimento de impotência no cotidiano de sua existência. São descritas as faltas de recursos financeiros, ... a família por não ter condições, ter condições zero, vive na miséria... (Pedro - Grupo 1); sociais, e de conhecimento, ... as famílias não estão preparadas para lidar com esse tipo de situação e por outro lado não têm, às vezes, a quem recorrer....(João - Grupo 1); e emocionais: ...é uma história (o surgimento da doença mental) totalmente diferente que exige de você o equilíbrio para suportar isso e muitas famílias não conseguem receber essa sobrecarga diante dos imprevistos, e isso dificulta muito sua vida e eu tenho passado por essas experiências (Cláudio - Grupo 2). E, como conseqüências, a família não tem controle da situação, acaba internando o doente mental e/ou vive um intenso sofrimento. Na maioria das vezes, a internação desejada de modo permanente ou efetivada em momentos de crise, é um recurso do qual as famílias não podem prescindir ${ }^{(3)}$.

Aqui é visualizada a família de classe popular, designando a população pobre dos centros urbanos, que é caracterizada pela precariedade de condições de vida ${ }^{(14)}$. Precariedade esta acentuada, quando a família passa a conviver com a enfermidade mental, constituindo num momento crítico do seu ciclo de desenvolvimento, pois reduz os rendimentos e gera conflitos que atingem as relações entre seus membros e entre estes e o domínio público ${ }^{(1)}$. Um dos participantes se inclui nesse tipo de organização familiar e comenta a sobrecarga. São grandes as carências familiares em termos materiais, psicossociais, educacionais e de qualidade de vida, descritas por eles e, embora esses sentimentos sejam um sentimento de classe, cada família organiza de modo diferente a maneira como lida com o problema da doença mental e vai cumprindo como pode o seu papel de cuidadora ${ }^{(1)}$. 
De uma forma ou de outra, os discursos dos participantes deste estudo apontam que as famílias pobres precisam de apoio e de investimentos por parte dos serviços públicos no atendimento à sua saúde.

e)A família como produtora de maus-tratos

Nesse tema, agrupamos repertórios que explicitavam a família do doente mental por ações de abandono, desinteresse, rejeição, uso indevido da renda do doente e exclusão doméstica. Um exemplo dessas construções é dado na fala a seguir.

... A família não dá um passo ... se aproveita do salário do doente, mas para ajudar não o faz, não investe naquilo que é a base da fonte de renda. A questão é tão grande que eles são capazes de usar uma pessoa dessa como fonte de renda (João - Grupo 1).

Esses repertórios falam-nos de uma família que não trata ou que maltrata seu doente. Se analisarmos esse sentido com outros que já foram, aqui, construídos, podemos visualizá-lo como uma implicação da falta de condições que tem a família pobre para cuidar do doente. De fato, a rejeição parece estar relacionada a condições materiais muito precárias, aliadas a um comportamento do doente mental bastante inadequado ${ }^{(3)}$. Por outro lado, compartilhamos da idéia de que, mesmo em condições de pobreza, pode haver a criação de recursos que possibilitem esse cuidado na comunidade ${ }^{(15)}$, não justificando os maustratos que são referidos, como rejeição, exclusão e exploração. Mesmo assim, tais sentidos devem ser entendidos com cautela, para que não impliquem uma relação de imposição ou distanciamento dos profissionais de saúde para com essas famílias, pois elas não são as únicas responsáveis pelo cuidado ao doente mental, como, muitas vezes, são descritas, de maneira que a postura de compartilhar problemas e escapes deve ser buscada, para construção de convivência saudável e de outros saberes e práticas que facilitem tal convivência.

f) Afamília desequilibrada

Esse tema surgiu das falas dos participantes que atribuíam desequilíbrio a todos os membros de algumas famílias que convivem com o doente mental, inviabilizando-as de oferecerem o cuidado de que ele necessita.

Quando você vê a história dele (referindo-se a um doente mental) você percebe na mãe um certo desequilíbrio, inclusive do pai, em toda a família, quer dizer, eles não têm como dar atenção a uma pessoa dessa, aí termina ficando na rua (Cláudio - Grupo 2).

O sentido de desequilíbrio, descrito nessa fala, remete-nos a uma construção depreciativa da família do doente mental, resultando não apenas na exclusão do doente como está visualizado na própria fala, como também num distanciamento dos profissionais de saúde dessa família, pois impõe um impedimento para sua aproximação, devido à impossibilidade de construção de qualquer coisa que seja favorável a sua existência. Para essa família, inscreve-se, também, um grau zero de trocas sociais. $E$ isso é fruto da cultura manicomial, enraizada na comunidade e reproduzida nas instâncias formadoras desses profissionais. Tal cultura considera o desequilíbrio como causa ou conseqüência da enfermidade mental, implicando um certo olhar, um certo gesto que classifica desclassificando, que inclui excluindo, que nomeia desmerecendo, que vê sem olhar ${ }^{(16)}$. E, portanto, contribui muito para acentuar os sentimentos de culpa, impotência e frustração experimentados pelas famílias do doente mental.

Sendo assim, esse sentido de desequilíbrio fecha o diálogo para novas construções das relações entre os profissionais e a família do doente mental, e entre estes e a comunidade. Mas, como este é um sentido que convive com outros apresentados aqui, há abertura para que ele, também, seja desfamiliarizado, abrindo portas para novas construções e relações.

\section{CONSIDERAÇÕES FINAIS}

Os sentidos produzidos pelos profissionais de saúde da família são diversos. Alguns contribuem para reforçar a exclusão do doente mental e de sua família, outros, porém, possibilitam romper com essa prática e promover aproximação dos profissionais com esses atores sociais. Essa aproximação é relevante e deve ser motivada, tendo em vista a promoção da saúde mental da população assistida por profissionais que integram o PSF.

Certamente, esses profissionais podem favorecer transformações na forma de a família lidar com o seu doente, partindo, inclusive, dos sentidos que ele dá e que rompe com a prática habitual da exclusão. São eles: a família como cuidadora e alvo do cuidado em saúde, a família como sofredora de preconceitos, a família inscrita por laços de parentesco e/ou afetivos e a família carente de recursos.

Dessa maneira, este trabalho pode favorecer outras reflexões acerca dos sentidos que foram construídos, em direção às propostas de atenção às famílias que convivem com o doente mental e que estão inseridas em áreas de atuação do PSF, aumentando, assim, o número de atores sociais responsáveis pelos cuidados dirigidos a essas pessoas. E, em direção a esses novos atores, profissionais de saúde da família, os serviços e nós, profissionais de saúde mental, precisamos refletir sobre as formas de oferecer-lhes suporte no desenvolvimento desse cuidado.

Outro ganho dessa produção está em fornecer ao leitor contribuições acerca dos sentidos que são produzidos por profissionais de saúde da família, no campo da Saúde Mental, podendo servir de ferramenta às suas próprias construções teóricas e práticas que abordam esse tema.

Nesse sentido, o diálogo, aqui produzido, está em aberto... 


\section{REFERÊNCIAS BIBLIOGRÁFICAS}

1. Souza RC, Pereira MAO, Scatena MCM. Família e transformação da atenção psiquiátrica: olhares que se (des) encontram. Rev Gaúch Enfermagem 2002 julho; 23(2):68-80.

2. Melman J. Família e doença mental: repensando a relação entre profissionais de saúde e familiares. São Paulo (SP): Escrituras Editora; 2001.

3. Gonçalves AM, Sena RR. A reforma psiquiátrica no Brasil: contextualização e reflexos sobre o cuidado com o doente mental na família. Rev Latino-am Enfermagem 2001 março; 9(2):48-55.

4. Waidman MAP, Stamm M. Família e saúde mental. Ciência, Cuidado e Saúde 2003 outubro; 2(suplemento):53-5.

5. Colvero LA. Desafios da família na convivência com o doente mental: cotidiano conturbado. [tese]. São Paulo (SP): Escola de Enfermagem/ USP; 2002.

6. Spink MJ, Medrado B. Produção de sentidos no cotidiano: uma abordagem teórico-metodológica para análise das práticas discursivas. In: Spink MJ, organizador. Práticas discursivas e produção de sentidos no cotidiano: aproximações teóricas e metodológicas. São Paulo (SP): Cortez; 1999.

7. Macnamee S, Gergem KL. Aterapia como construção social. Porto Alegre (RS): Artes Médicas; 1998.

8. Souza, RC. Produção de sentidos por profissionais de saúde da família acerca do doente mental e dos cuidados a ele dirigidos. [tese]. Ribeirão Preto (SP): Escola de Enfermagem de Ribeirão Preto/USP; 2004.

9. Spink MJ, organizador. Práticas discursivas e produção de sentidos no cotidiano: aproximações teóricas e metodológicas. São Paulo (SP): Cortez; 1999.

10. Monteiro, ARM, Barroso, MGT. A família e o doente mental usuário do hospital-dia: estudo de um caso. Rev Latino-am Enfermagem 2000 dezembro; 8(6):20-6.

11. Melman, J. Intervenções familiares no campo da reforma psiquiátrica. In: Fernandes MIA, Scarcelli IR, Costa ES, organizadores. Fim de século: ainda manicômios? São Paulo (SP): IPUSP; 1999. p. 171-86. 12. Romanelli G. Políticas de saúde e famílias de classes populares. In: Encontro Anual da ANPOCS, 23., 1996. São Paulo (SP): HUCITEC; 2001. p.81-4.

13. Grandesso M. Sobre a reconstrução do significado: uma análise epistemológica e hermenêutica da prática clínica. São Paulo (SP): Casa do Psicólogo; 2000.

14. Romanelli G. Família de classes populares: socialização e identidade masculina. Cad Pesqui 1997; 1/225-34.

15. Saraceno B. Libertando identidades: da reabilitação psicossocial à cidadania possível. Belo Horizonte (MG): Te Corá Editora/Instituto Franco Basaglia; 1999.

16. Amarante P. Manicômio e loucura no final do século e do milênio. In: Fernandes MIA, Scarcelli IR, Costa ES, organizadores. Fim de século: ainda manicômios? São Paulo (SP): IPUSP; 1999. p. 47-53. 